\title{
Abordagens lúdicas e o enfrentamento do tratamento oncológico na infância
}

\author{
Playful approaches and coping with childhood cancer treatment \\ Enfoques lúdicos y afrontamiento del tratamiento del cáncer infantil
}

\author{
Nadja Caroline Bezerril Lopes' @; Ana Cláudia Gomes Viana' @; Zirleide Carlos Félix' @; \\ Jancelice dos Santos Santana' @ ; Patrícia Tavares de Limal @ ; Ana Lúcia de Medeiros Cabral’ @
}

'Centro Universitário UNIESP, Cabedelo, PB, Brasil

\begin{abstract}
RESUMO
Objetivo: demonstrar como, na percepção da criança acometida por câncer, as abordagens lúdicas contribuem para que ela enfrente o tratamento oncológico. Método: trata-se de um estudo qualitativo, descritivo e exploratório. Procedeu-se à entrevista semiestruturada com dez crianças com idades entre 6 e 12 anos acolhidas em uma casa de apoio. Para analisar as informações, optou-se pela técnica de análise de conteúdo. Resultados: emergiram duas categorias: o significado de brincar na compreensão da criança em tratamento oncológico; os sentimentos revelados a partir do brincar durante o tratamento oncológico. As crianças disseram que acham importante brincar durante o tratamento e reconhecem que, ao brincar, vivenciam uma variedade de sentimentos, como felicidade e bem-estar, mas também raiva por sentir dor devido à condição de estar doente. Conclusão: as abordagens lúdicas são ferramentas essenciais para auxiliar a criança a vivenciar as diferentes situações na doença e no tratamento.
\end{abstract}

Descritores: Pediatria; Enfermagem Pediátrica; Criança Ludoterapia; Oncologia.

\begin{abstract}
Objective: to demonstrate how, in the children's view, playful approaches contribute to their coping with cancer treatment. Method: this qualitative, descriptive, exploratory study involved semi-structured interviews of ten children between 6 and 12 years old. Content analysis was used to analyze the information obtained. Results: two categories emerged: the meaning of play as understood by children undergoing cancer treatment; and the feelings revealed through play during cancer treatment. The children said they though it important to play during treatment and recognized that, when playing, they experienced a variety of feelings, such as happiness and well-being, but also anger at feeling pain due to the condition of being ill. Conclusion: playful approaches are essential tools for helping children in the various different situations they experience in their illness and treatment.

Descriptors: Pediatrics; Pediatric Nursing; Childhood; Play therapy; Oncology.

\section{RESUMEN}

Objetivo: demostrar cómo, desde el punto de vista de los niños, los enfoques lúdicos contribuyen a hacer frente al tratamiento del cáncer. Método: este estudio cualitativo, descriptivo y exploratorio involucró entrevistas semiestructuradas a diez niños de entre 6 y 12 años. Se utilizó el análisis de contenido para analizar la información obtenida. Resultados: surgieron dos categorías: el significado del juego tal como lo entienden los niños en tratamiento contra el cáncer; y los sentimientos revelados a través del juego durante el tratamiento del cáncer. Los niños dijeron que les parecía importante jugar durante el tratamiento y reconocieron que, al jugar, experimentaban una variedad de sentimientos, como felicidad y bienestar, pero también ira al sentir dolor debido a la condición de estar enfermo. Conclusión: los enfoques lúdicos son herramientas esenciales para ayudar a los niños en las diferentes situaciones que experimentan en su enfermedad y tratamiento.

Descriptores: Pediatría; Enfermería Pediatrica; Niño; Ludoterapia; Oncología.
\end{abstract}

\section{INTRODUÇÃO}

O câncer é considerado a primeira causa de morte na faixa etária de um a 19 anos e representa $8 \%$ do total de morte nesse período da vida. Devido à significativa evolução ocorrida nas últimas quatro décadas nas modalidades terapêuticas, hoje, aproximadamente $80 \%$ das crianças e dos adolescentes acometidos pela doença podem ser curados, se diagnosticados precocemente e tratados em centros especializados ${ }^{1}$.

Após o diagnóstico, a criança passa a ser submetida a diversos procedimentos, como exames, procedimentos invasivos, quimioterapia, radioterapia, cirurgia, dentre outros e fica com limitações físicas, sociais e emocionais ${ }^{2,3}$. Assim, ela irá sentir o impacto do câncer, porque isso afeta sua escolarização, que é interrompida, o convívio social e familiar. Todos esses aspectos podem interferir em sua aptidão e na vontade de brincar ${ }^{4}$.

Por essa razão, é fundamental que ela possa usufruir de instrumentos de seu domínio e conhecimento para se adaptar a essa nova situação. É nessa perspectiva que as atividades lúdicas são vistas como capazes de proporcionar prazer e felicidade e de resgatar a essência da criança nesse processo de cuidar. Assim, ao brincar, a criança pode enfrentar situações estressantes, como o câncer e seu tratamento ${ }^{5}$. 
A palavra lúdico, etimologicamente, deriva do latim, 'ludus', que significa alegria e liberdade, comumente presentes nas brincadeiras infantis. Quando essas atividades são aplicadas de forma adequada, podem contribuir para as descobertas cognitivas, afetivas, motoras, sociais e de comunicação necessárias à criança que vivencia o câncer 6 .

A imprescindibilidade de se divertir não deve ser eliminada durante a doença e o tratamento, uma vez que a diversão possibilita a expressão de sentimentos, preferências, receios e hábitos a partir de sua projeção e transferência para os personagens da brincadeira, criando um faz de conta. Por isso, o lúdico proporciona às crianças uma maneira mais prazerosa de viver uma nova rotina, até então desconhecida para ela, e evita que a experiência de estar com câncer seja atrelada apenas a sentimentos negativos ${ }^{7,8}$

É nessa perspectiva que se insere a necessidade da brincadeira terapêutica, que auxilia a criança a enfrentar uma doença tão complexa como o câncer. Os atos de brincar, pintar, cantar e dançar, ou seja, de fazer com que a criança realize durante o tratamento as atividades que lhes são comuns e rotineiras, podem resultar na diminuição do estresse, da angústia e do medo associado à doença, ao tratamento e aos procedimentos realizados pela equipe de saúde, transformando a percepção que elas têm acerca da doença e do tratamento ${ }^{9}$.

Nesse cenário, as abordagens lúdicas ,quando empregadas adequadamente, são importantes por poder levar a criança a encontrar um motivo para sorrir, dando-lhe voz para que se expresse sobre o ato de brincar e manifeste seus sentimentos adquiridos no processo terapêutico. Dessa maneira, as abordagens supracitadas contribuem para que se possam compreender bem mais como esse recurso pode contribuir com o enfrentamento do tratamento oncológico.

Ante o exposto, este estudo teve o objetivo de mostrar como, na percepção da criança, as abordagens lúdicas contribuem para que elas possam enfrentar o tratamento oncológico.

\section{MÉTODO}

Estudo descritivo exploratório, com abordagem qualitativa, realizado na Casa de Apoio à Criança com Câncer, situada no município de João Pessoa, PB - Brasil, local que oferece hospedagem com alimentação e transporte para deslocamento até o hospital, atividades recreativas e oficinas para as crianças e seus familiares acompanhantes.

A população do estudo compôs-se de 26 crianças em tratamento oncológico ambulatorial que estavam albergadas no referido local, no período de agosto a setembro de 2018, quando os dados foram coletados. Para selecionar a amostra, foram adotados os seguintes critérios de inclusão: que os possíveis participantes estivessem na faixa etária entre 6 e 19 anos e tivessem o consentimento dos pais para participarem do estudo. Como critério de exclusão, foram dispensadas as crianças que estavam em isolamento devido ao comprometimento imunológico relacionado à toxicidade associada aos efeitos colaterais do tratamento. A amostra foi composta por acessibilidade e foi constituída de dez crianças. Inicialmente, como não foi definido o tamanho da amostra, foi empregado o critério de saturação dos dados, que ocorre quando se constata a repetição das informações obtidas nas falas das crianças participantes.

Os dados foram coletados em duas etapas. Na primeira, foi seleciona a amostra de forma intencional e auxiliada pela equipe da Casa de Apoio à Criança com Câncer, que indicava possíveis participantes conforme os critérios supracitados. No prontuário, buscaram-se a idade, o tipo de câncer, os nomes dos pais e o estado geral da criança. Inicialmente a pesquisadora manteve contato com os pais da criança para informar sobre o estudo e solicitar autorização para a criança participar, mediante assinatura do Termo de Consentimento Livre e Esclarecido e do Termo de Assentimento Livre e Esclarecido para as crianças, resguardando, contudo, o direito de negar a participação no estudo. Todos permitiram a participação das crianças.

Na segunda etapa, a criança foi abordada individualmente e convidada a participar da entrevista, que aconteceu em uma brinquedoteca existente na casa de apoio, por ser um espaço reservado, onde a criança responder as seguintes perguntas: O que é brincar? Qual a importância do brincar? Quais as brincadeiras de que costuma participar depois que ficou doente? O que a criança sente quando está brincado? Também foi investigado sobre quais brincadeiras costumam realizar quando estão no hospital e na casa de apoio.

A entrevista durou, em média, trinta minutos. Os depoimentos foram gravados com o auxílio tecnológico de um aparelho MP3 e identificados pela letra C, relativa à palavra criança, a fim de preservar o anonimato dos entrevistados.

Submeteram-se os dados obtidos pelas entrevistas à técnica de Análise de Conteúdo, obedecendo-se aos seguintes passos: organização e transcrição das falas; leitura profunda das entrevistas; identificação e categorização dos núcleos significativos; inferência dos resultados e interpretação dos dados com base na fundamentação teórica ${ }^{10}$.

Em cumprimento à Resolução no 466/2012, do Conselho Nacional de Saúde (CNS), os dados só foram coletados depois do recebimento da certidão de aprovação pelo Comitê de Ética do Instituto de Educação Superior da Paraíba (IESP), sob o número do parecer: $2.759 .893^{11}$. 


\section{RESULTADOS}

Todas as crianças entrevistadas têm residência fixa no interior da Paraíba, porque o local selecionado para a realização do estudo acolhe crianças e seus familiares que residem em lugares distantes do município onde fica o hospital de referência para o tratamento oncopediátrico. A Figura 1 apresenta a caracterização dos participantes do estudo.

\begin{tabular}{|c|c|c|c|c|c|c|}
\hline Código & Idade & Sexo & $\begin{array}{l}\text { Tempo de } \\
\text { tratamento }\end{array}$ & Tipo de câncer & $\begin{array}{l}\text { Tipo de } \\
\text { tratamento }\end{array}$ & Frequência escolar \\
\hline $\mathrm{C} 1$ & 7 anos & $\mathrm{M}$ & Mais de 1 ano & $\begin{array}{l}\text { Histiocitose de células } \\
\text { de langerhans }\end{array}$ & Quimioterapia & Sim \\
\hline $\mathrm{C} 2$ & 6 anos & $M$ & $\begin{array}{l}\text { Menos de } 6 \\
\text { meses }\end{array}$ & $\begin{array}{l}\text { Não identificado no } \\
\text { prontuário }\end{array}$ & Quimioterapia & $\begin{array}{l}\text { Quando é liberada } \\
\text { pelo médico }\end{array}$ \\
\hline C3 & 8 anos & $M$ & Mais de 1 ano & Linfoma & Quimioterapia & Não \\
\hline C4 & 11 anos & $\mathrm{F}$ & $\begin{array}{l}\text { Entre } 6 \text { meses a } \\
1 \text { ano }\end{array}$ & Leucemia & Quimioterapia & Sim \\
\hline C5 & 12 anos & $M$ & $\begin{array}{l}\text { Entre } 6 \text { meses a } \\
1 \text { ano }\end{array}$ & Neuroblastoma & Quimioterapia & Não \\
\hline C6 & 9 anos & $M$ & Mais de 1 ano & Tumor cerebral & Radioterapia & Não \\
\hline $\mathrm{C7}$ & 12 anos & $M$ & Mais de 1 ano & Leucemia & Quimioterapia & Não \\
\hline C8 & 12 anos & $M$ & $\begin{array}{l}\text { Entre } 6 \text { meses a } \\
1 \text { ano }\end{array}$ & Sarcoma & Quimioterapia & Não \\
\hline C9 & 9 anos & $M$ & Mais de 1 ano & Leucemia & Quimioterapia & Não \\
\hline C10 & 11 anos & M & $\begin{array}{l}\text { Entre } 6 \text { meses a } \\
1 \text { ano }\end{array}$ & Leucemia & Quimioterapia & Não \\
\hline
\end{tabular}

FIGURA 1: Caracterização das crianças participantes do estudo (n=10). João Pessoa, PB, Brasil, 2020.

Participaram do estudo 10 crianças, entre seis e 12 anos, estando a maioria em quimioterapia. 0 tempo de tratamento menos de seis meses e mais de um ano e sete não apresentavam frequência escolar.

Depois de analisar os depoimentos das participantes do estudo, foi possível compreender como as abordagens lúdicas contribuem para que as crianças enfrentem o tratamento oncológico, conforme apresentado nas Categorias 1 e 2.

\section{Categoria 1: O significado de brincar na compreensão da criança em tratamento oncológico}

Nessa categoria, constatou-se que a brincadeira faz com que as crianças não estejam completamente privadas de uma atividade que, naturalmente, faz parte de seu cotidiano. Para elas, a brincadeira associa-se a diversão, conforme demonstrado nestas falas:

$$
\begin{aligned}
& \text { Brincar pra mim é se divertir (C2, } 6 \text { anos). } \\
& \text { Brincar é se divertir (C5, } 12 \text { anos). } \\
& \text { É uma diversão e passa tempo (C8, } 12 \text { anos). }
\end{aligned}
$$

Percebe-se que, na compreensão infantil, as brincadeiras durante o tratamento são consideradas importantes para que o momento não seja permeado apenas por seriedade e ociosidade, conforme expressado por C2, C4 e C6:

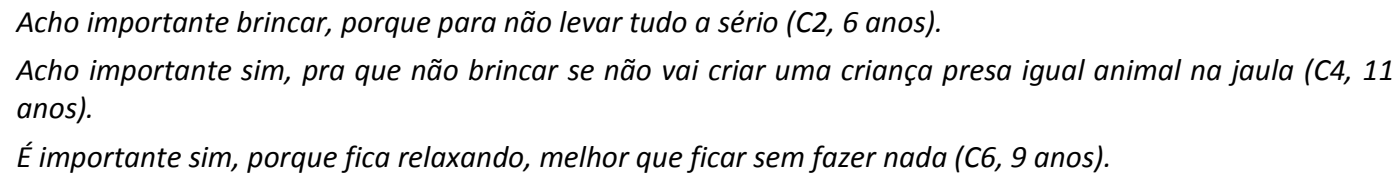

A fala de C4 expressa claramente que, ao brincar, a criança vivencia o sentimento de liberdade, visto que o não brincar, na compreensão dela, significa "ficar presa igual a um animal na jaula".

Apesar da importância que as crianças dão às brincadeiras durante o tratamento da doença, as falas abaixo demonstram certa escassez dessas atividades enquanto elas estão no hospital, como dito por C1 e C4:

Não brincava de nada no hospital, mas queria que tivesse, porque seria mais divertido. A única coisa que brincava lá era com aquele negócio de ferro que bota soro, eu descia da cama e fazia de skate, isso me dava alegria (C1, 7 anos).

Brinco na brinquedoteca é a única brincadeira lá (C4, 11 anos).

O fato de as atividades lúdicas não serem realizadas sistematicamente durante a hospitalização pode contribuir para a utilização dos recursos tecnológicos como meio de ocupação do tempo:

Brinco de nada quando tô lá fico só no celular (C8, 12 anos). 
Lá não tem brincadeira, fico no celular mexendo e os palhaços que às vezes vão lá só dar presente (C5, 12 anos).

Quando as brincadeiras não são planejadas conforme a faixa etária do paciente, pode não ser considerada como atrativa, como expressa C10.

Brinco só no celular, não gosto dos palhaços, estou velho pra achar graça nisso (C10, 11 anos).

Pontua-se a observância de um leque maior das brincadeiras realizadas com as crianças durante sua permanência na Casa de Apoio, como se observa a seguir:

Às vezes, brinco com o bambolê e de carro com os meninos que estão aqui (C2, 6 anos).

Brinco de bola, carrinho, pega-pega, e com as tias que vem pra cá (C4, 11 anos).

Gosto de brincar no celular, baralho e com uma menina igual a senhora que vem pra cá (C10, 11 anos).

Quando interrogadas acerca do interesse pelas brincadeiras realizadas na Casa da Criança, onde ficam hospedadas durante o tratamento, algumas crianças demonstraram desinteresse pelas atividades, como C3 e C10:

Não, não gosto de brincar, brinco às vezes quando vem os palhaços ainda das brincadeiras, mas é às vezes (C3, 8 anos).

Não brinco muito, só de vez em quando, o que gosto mesmo é de andar a cavalo (C10, 11 anos).

A vivência de uma doença tão complexa durante a infância demanda um amadurecimento precoce da criança, e ela passa a compreender a necessidade de ajustar seu cotidiano. Tal fato é demonstrado quando elas falam que têm medo de se machucar e de agravar a doença, conforme mostra estes depoimentos:

Brinco de quase todas as brincadeiras, menos de espada que pode bater na minha cabeça e eu piorar (C6, 9 anos).

É importante mais ou menos, porque "mode" da doença, porque se eu tô doente e for brincar, fica mais grave (C8, 12 anos).

\section{Categoria 2: Os sentimentos revelados a partir do brincar durante o tratamento oncológico}

Essa categoria expressa as falas das crianças e reflete sua percepção sobre os diversos sentimentos vivenciados a partir da participação nas atividades lúdicas realizadas durante o tratamento. Nesse sentido, observou-se que a maioria expressou sentimentos positivos durante o envolvimento nas brincadeiras realizadas.

Para algumas crianças, os sentimentos expressados ao brincar são a alegria e a felicidade, podendo inclusive proporcionar momentaneamente o esquecimento dos eventos associados à doença, conforme descrito abaixo:

Sinto felicidade [...] achei que fiquei melhor quando brinquei ( $C 1,7$ anos).

Me sinto bem e feliz, me faz esquecer um pouco do que tá acontecendo (C2, 6 anos).

Sinto alegria e raiva quando tô perdendo (C8, 12 anos).

Diversão (C7, 12 anos).

Mas, a depender da etapa do tratamento, algumas crianças demonstraram que sentem medo de participar das atividades porque podem sentir dor e a doença se agravar.

Me sinto cansado e sinto dor quando brinco muito (C6, 9 anos).

Sinto dor e fico com raiva quando sinto dor (C9, 9 anos).

De acordo com os relatos de C6 e C9, a dor é uma sensação frequente em pacientes acometidos pelo câncer, podendo, inclusive, ocasionar o sentimento de raiva, conforme expressado por C9.

Para as crianças que estiveram momentaneamente impossibilitadas de participar de atividades mais dinâmicas como o correr, o fato de poderem voltar a fazer esse movimento resgatou o sentimento de felicidade e contribuiu para que o olhar da criança não se volte apenas para as consequências associadas ao tratamento como a alopécia, por exemplo.

Sim, porque não conseguia andar e quando consegui andar vi que é importante brincar e fiquei feliz (C4, 11 anos).

Humhum...porque trouxe alegria e tô conseguindo correr, me fez esquecer que estou careca (C6, 9 anos).

Notou-se, todavia, que o medo é um sentimento que também pode ser vivenciado, porquanto algumas crianças acreditam que as brincadeiras durante o tratamento não as ajudam a melhorar, ao contrário, acham que brincar piora a doença.

Não, porque quando brinco pioro (C8, 12 anos).

Não, quando estou brincado não me faz esquecer (C5, 12 anos).

Não sinto nenhuma melhora, não gosto de brincar (C3, 8 anos).

Não ajuda! Minha mãe me faz lembrar dos remédios, ela tem medo que eu piore (C9, 9 anos). 


\section{DISCUSSÃO}

O estudo mostrou que brincar é uma forma de trazer a diversão para uma nova rotina modificada em decorrência das limitações impostas pelo câncer as crianças que se encontram na casa de apoio para tratamento clínico, caracterizando-se como um evento modificador da rotina de "ser criança". Verificou-se que as abordagens lúdicas se constituem em importante ferramenta de enfrentamento do câncer infanto-juvenil, pois proporcionam momentos alegres e divertidos.

O brincar tem um importante valor terapêutico para crianças com câncer, porque lhes proporciona bem-estar físico e emocional e, consequentemente, ajuda-as a se recuperar ${ }^{12}$.

O estudo indicou que as crianças participantes desta pesquisa compreendem que brincar é muito importante, sobretudo porque proporciona uma distração momentânea, que faz com que se esqueçam da doença, e que é um recurso que ajuda a passar o tempo, enquanto ficam ociosas quando estão na casa de apoio. Tal achado se assemelha aos resultados obtidos por meio do relato de crianças que associam a brincadeira a algo que as faz felizes ${ }^{4}$.

Assim, o brincar exerce uma grande importância no desenvolvimento infantil e colabora para a apreensão de comportamentos e a construção do conhecimento sobre a realidade em que a criança está inserida, como expressão de sentimentos e emoções. Considerando que a criança acometida pelo câncer apresenta mudanças na forma orgânica e na psicossocial, a brincadeira pode diminuir a ansiedade e o medo diante do desconhecido ${ }^{13,14}$.

As abordagens lúdicas trazem para a criança um momento só seu, em que podem descobrir o mundo com sua imaginação e as brincadeiras, esquecer-se do mundo real e se agarrar em seu faz de conta, trazendo para o mesmo uma realidade que ela cria, fazendo com que aquele momento de tratamento traga um motivo para sorrir ${ }^{15,16}$.

Foi possível identificar que as crianças percebem a importância que as brincadeiras representam para que enfrentem o diagnóstico e o tratamento do câncer. Contudo, é imprescindível que profissionais de Saúde envolvidos nos cuidados reconheçam o potencial das abordagens lúdicas para desmistificar a ideia de que o tratamento oncológico é apenas um período de sofrimento e dor e pode, inclusive, ser utilizada como recurso para preparar a criança para se submeter a procedimentos como biópsia, punção venosa, sondagem, dentre outros, que não faziam parte do universo da criança antes do diagnóstico ${ }^{17,18}$.

Além disso, embora seja importante manter as brincadeiras na rotina das crianças, seus discursos indicaram que o período de tratamento é um universo de brincadeiras limitado, porque foram relatadas poucas atividades durante esse momento, principalmente durante a estadia no ambiente hospitalar. Entre os fatores associados à escassez de brincadeiras, destaca-se a sobrecarga de trabalho imposta à equipe de saúde, porém esses profissionais precisam ter ciência das muitas possibilidades que o brincar pode oferecer a eles próprios e à criança. Então, apesar da sobrecarga, é importante incluir as conversas, a contação de histórias e as brincadeiras na assistência à criança em tratamento oncológico ${ }^{19}$.

Nesse cenário, a equipe de enfermagem se destaca, por estar presente no dia a dia da criança nos diversos cuidados, como alimentação, higiene, administração de medicamentos, coleta de material para exames, etc. Porém, além de priorizar o manejo da doença, não se deve esquecer de incluir as brincadeiras nesse contexto, porque elas propiciam uma assistência humanizada, com o fim de atender à criança integralmente ${ }^{20}$.

É compreensível que, em virtude da doença, as atividades lúdicas realizadas com essas crianças, durante o tratamento do câncer, necessitem de adequação, e as que se destacaram entre os participantes foram: brinquedoteca, sorteios, visita de palhaços "voluntários", fazer o suporte de soro de skate e uso do celular. Pesquisa aponta a brinquedoteca como o principal local de brincadeira utilizado por crianças com câncer e destaca a potencialidade do espaço por possibilitar que a criança expresse suas emoções e aprendam um novo modo de brincar compatível com sua atual condição de saúde ${ }^{4}$.

Quando as crianças são acolhidas na Casa da Criança, podem brincar de bambolê, de carro, de pega-pega e de baralho e podem usar o celular para se divertir. Como essas atividades proporcionam a construção do vínculo e o fortalecimento dos laços de amizade entre as crianças, elas sentem vontade de brincar, e isso se reflete em momentos mais divertidos e alegres.

Brincadeiras como bambolê e pega-pega incentivam as crianças a serem ativas e atuam como coadjuvantes para combater comorbidades associadas à inatividade física, como obesidade infantil, doenças cardiovasculares e diabetes ${ }^{21}$. Todavia, uns dos itens que se destacaram entre as crianças foi o uso do celular, utilizado como recurso eletrônico como forma de diversão, mas que contribui para diminuir as brincadeiras em grupo e, consequentemente, a interação entre as crianças. A esse respeito, um estudo realizado com 4.500 crianças americanas, com idades entre 8 e 11 anos, apontou que o uso de dispositivos eletrônicos, como celulares, tablets e computadores, por mais de duas horas diárias, prejudica o desenvolvimento cognitivo da criança e que o uso prolongado pode comprometer o sono, os estudos ou as interações pessoais presenciais ${ }^{22}$. 
É importante ressaltar que, pelo fato de a doença acarretar um amadurecimento precoce da criança, algumas ponderam sobre sua participação em determinadas atividades por acreditar que podem evoluir para piorar a doença por causa de determinadas brincadeiras mais dinâmicas que possam gerar impacto. Tal fato é compreensível, visto que a difícil rotina de uma criança com câncer pode provocar limitações, incapacidades físicas e psicológicas e interferir em sua capacidade e em seu desejo de brincar ${ }^{9}$.

Em relação à expressão dos sentimentos, quando participam das brincadeiras, destacaram-se a felicidade, a alegria e o sentir-se bem. O brincar também foi mencionado como um recurso para não levar tudo a sério e para ajudar a se esquecer da realidade, ou seja, do fato de estar com câncer. Atestando esses resultados, autores apontam o desenvolvimento da criatividade como um dos principais benefícios das abordagens lúdicas durante o tratamento, pois o infante utiliza as abordagens lúdicas para criar seu faz de conta e seu mundo, e isso faz com que toda aquela realidade ganhe um pouco de alegria e diversão ${ }^{23,24}$.

Observou-se, também, que as crianças têm medo de sentir dor e de piorar da doença pelo fato de brincar. Todavia, é compreensível que a doença e o tratamento desencadeiem os sentimentos de ansiedade e de medo, principalmente o de sentir dor ${ }^{25}$. A raiva também esteve entre os sentimentos mencionados sobre querer brincar e não conseguir devido à sensação de dor. Convém enfatizar que a experiência vivida pela doença é dolorosa para a criança que, antes, podia saltar, pular e correr sem nenhum incômodo, o que pode gerar um sentimento negativo associado a raiva ${ }^{26,27}$.

Os resultados deste estudo podem colaborar para que os profissionais da área de Saúde, os familiares e os voluntários, aqui representados por professores e estudantes do Curso de Graduação em Enfermagem que desenvolvem um projeto de extensão com essas crianças, possam refletir sobre a necessidade de incluir o brincar no cotidiano das crianças submetidas a tratamento oncológico. As brincadeiras auxiliam a reduzir o estresse, a ansiedade e o desconforto gerados pela doença e podem contribuir para que elas se socializem com outras crianças, com o profissional de saúde, com a equipe da casa de apoio e com a família.

Nesse sentido, o brincar passa a ser visto como um espaço terapêutico, que pode não só promover a sequência do desenvolvimento infantil, como também possibilitar que a criança compreenda o momento específico que está vivenciando. A brincadeira é uma linguagem universal por meio da qual as crianças se expressam. Uma conexão adequada entre brincar e enfrentar os aspectos diversos da vida pode ajudar as crianças a se desenvolverem e a se tornarem mais resilientes ao enfrentar as adversidades ${ }^{28}$.

\section{CONCLUSÃO}

Constatou-se que, quando brincavam, as crianças se esqueciam, por um momento, que estavam com câncer, porque a brincadeira desperta sentimentos de felicidade e de bem-estar. Contudo, o medo também esteve presente, porque algumas crianças o associaram ao risco de piorar da doença. A raiva também foi mencionada por sentir dor ao brincar.

Quanto às atividades realizadas, apesar de ter sido oferecida uma variedade delas, algumas crianças participantes desta pesquisa preferiram utilizar o celular para se distrair, o que pode interferir na interação com os demais indivíduos presentes no ambiente.

Por fim, ressalta-se que, como esta pesquisa foi restrita à casa de apoio, a generalidade dos resultados obtidos foi limitada. Portanto, recomenda-se que sejam produzidos novos estudos para se investigarem as abordagens lúdicas no cuidado voltado para a criança com câncer.

\section{REFERÊNCIAS}

1. Ministério da Saúde (BR), Instituto Nacional do Câncer. Câncer infantojuvenil - versão para profissionais de saúde [internet]. Rio de Janeiro: INCA; 2020 [cited 2020 july 15]. Available from: https://www.inca.gov.br/tipos-de-cancer/cancerinfantojuvenil/profissional-de-saude.

2. Sultan S, Leclair T, Rondeau E, Burns W, Abate C. A systematic review on factors and consequences of parental distress as related to childhood câncer. European Journal of Cancer Care [internet], 2016 [cited 2020 Jan 15]; 25: 616-37. DOI: https://doi.org/10.1111/ecc.12361.

3. Silva PLN, Xavier GC, Oliveira VV, Figueiredo ML, Prado PF, Filho WA. Childhood cancer: experiences of children in treatment oncologic. Enferm. Foco [internet], 2016 [cited 2020 Jan 15]; 7(3/4):51-5. Available from: http://revista.cofen.gov.br/index.php/enfermagem/article/view/916/346.

4. Silva LF, Cabral IE. Rescuing the pleasure of playing of child with cancer in a hospital setting. Rev. Bras. Enferm. [internet], 2015 [cited 2020 Jan 15]; 68(3):337-42. DOI: http://dx.doi.org/10.1590/0034-7167.2015680303i.

5. Sposito AMP, Schinzari NRG, Mitre RMA, Pfeifer LI, Lima RAG, Nascimento LC. The best of hospitalization: contributions of playing to cope with chemotherapy. Av Enferm. [internet], 2018 [cited 2020 Jun 20]; 36(3):328-37. DOI: https://doi.org/10.15446/av.enferm.v36n3.61319.

6. Santos SS, Alves ABSA, Oliveira JC, Gomes A, Maia LFS. Ludoterapia as a tool in humanized nursing care. Recien [internet]. 2017 [cited 2020 Jan 15]; 7(21):30. DOI: https://doi.org/10.24276/rrecien2358-3088.2017.7.21.30-40. 
7. Marques EP, Garcia TMB, Anders JC, Luz JH, Rocha PK, Souza S. Playful activities in health care for children and adolescents with cancer: the perspectives of the nursing staff. Esc. Anna Nery. [internet], 2016 [cited 2020 Jun 20]; 20(3):e20160073. Available from: https://www.scielo.br/scielo.php?script=sci_arttext\&pid=S1414-81452016000300218\&lng=en\&tlng=en.

8. Silva LAGP, Baran FDP, Mercês NNA. Music in the care of children and adolescents with cancer: integrative review. Texto Contexto Enferm. [internet], 2016 [cited 2020 Jun 20]; 25(4):E1720015. DOI: https://doi.org/10.1590/010407072016001720015.

9. Del Pino C, Pereira VT. Ludoterapia durante o tratamento contra o câncer infantil: revisão integrativa de literatura. Rev. Psicol. Foco [internet], 2017 [cited 2020 fev 15]; 9(14):26-44. Available from: http://revistas.fw.uri.br/index.php/psicologiaemfoco/article/view/2132/2488.

10. Bardin L. Análise de conteúdo. Lisboa: Edições 70, 2016.

11. Ministério da Saúde (BR), Conselho Nacional de Saúde. Resolução no 466/2012. Trata de pesquisas em seres humanos [Internet]. Brasília: Ministério da Saúde; 2012 [cited 2019 June 15]. Available from: http://conselho.saude.gov.br/resolucoes/2012/Reso466.pdf.

12. Koukourikos K, Tzeha L, Pantelidou P, Tsaloglidou A. The importance of play during hospitalization of children. Mater Sociomed. [internet], 2015 [cited 2020 Nov 07];27(6):438-441 Available from: https://pubmed.ncbi.nlm.nih.gov/26889107/.

13. França JRFS, Costa SFG, Lopes MEL, Nóbrega MML, Batista PSS, Oliveira RC. Existential experience of children with cancer under palliative care. Rev Bras Enferm [Internet], 2018 [cited 2020 Jun 27]; 71(Suppl 3):1320-7. DOI: http://dx.doi.org/10.1590/00347167-2016-0493.

14. Lima MS, Barbosa FAS, Monteiro LM. The importance of ludic to hospitalized children: Integrative review. Reon Facema [internet], 2015[cited 2020 Fev 15]; 1(2):139-142. Available from: https://www.facema.edu.br/ojs/index.php/ReOnFacema/article/view/54/35.

15. Bataglion GA, Marinho A. Family members of children with disabilities: perceptions regarding playful activities in rehabilitation. Ciênc saúde coletiva [internet], 2016 [cited 2020 Fev 15]; 21(10):3101-10. DOI: https://doi.org/10.1590/1413812320152110.19232016.

16. Carvalho TGP, Santos ARM, Silva ML, Leonídio ACR, Silva PPC, Caminha IO etal. O olhar do paciente sobre o câncer infantojuvenil e sua percepção acerca de seus sentimentos e emoções diante do videogame ativo. Movimento [internet], 2018 [cited 2020 Fev 15]; 24(2):413-26. DOI: http://dx.doi.org/10.22456/1982-8918.72695.

17. Dias PLM, Silva IP. The use of the toy during the treatment of children with cancer: perceptions of the multidisciplinary team. Rev. Bras. Cancerol. [internet], 2018 [cited 2020 Fev 15]; 64(3):311-8. DOI: https://doi.org/10.32635/21769745.RBC.2018v64n3.28.

18. Gomes AS, Ribeiro GP, Lima LS, Ferreira ES. Contribuição do brinquedo terapêutico na interação entre a criança, a família e a equipe de enfermagem. Rev. Enferm. Integrada. [internet], 2015 [cited 2020 Nov 07]; 8(2). Available from: http://www.unilestemg.br/enfermagemintegrada.

19. Freitas JAL, Oiliveira BLG. Psychological aspects involved in the survival of childhood cancer. Revista Uningá [internet], 2018 [cited $2020 \mathrm{Fev} 20$ ]; 55(2):1-13. Available from: http://revista.uninga.br/index.php/uninga/article/view/76.

20. Vieira APMS, Castro DL, Coutinho MS. Assistência de enfermagem na oncologia pediátrica. Rev. Eletrôn Atualiza Saúde [internet], 2016 [cited 2020 Nov 07]; 3(3):67-75. Available from: http://atualizarevista.com.br/wpcontent/uploads/2016/01/Assist\%C3\%AAncia-de-enfermagem-na-oncologia-pedi\%C3\%A1trica-v-3-n-3.pdf.

21. Truelove $S$, Vanderloo LM, Tucker P. Defining and measuring active play amongyoung children: a systematic review. J. Phys. Act. Health 2017 [cited 2020 Nov 07]; 14(2):155-66. DOI: https://doi.org/10.1123/jpah.2016-0195.

22. Ashton JJ, Beattie RM. Screen time in children and adolescents: is there evidence to guide parents and policy? The Lancet Child \& Adolescent Health [internet], 2019 Mar [cited 2020 Nov 07]; 3(5):292-4. DOI: https://doi.org/10.1016/S2352-4642(19)30062-8.

23. Pagung LB. Estratégias de enfrentamento e otimismo de crianças com câncer e crianças sem câncer. Rev. Psicol. Saúde [internet], 2017 [cited 2020 Jul 15]; 9(3):33-46. DOI: http://dx.doi.org/10.20435/pssa.v9i3.470.

24. Barros LF, Santos CJO, Moro TNP, Jeus VMF. Quality of life and cancer children and youth. Rev. Rede cuid. saúde [internet]. 2017 [cited 2019 June 15]; 10(1):1-13. Available from: http://publicacoes.unigranrio.edu.br/index.php/rcs/article/view/3125/2202.

25. Fontes CMB, Oliveira ASS, Toso AL. Therapeutic toy in pediatric intensive therapy unit. Rev. enferm. UFPE on line. [internet], 2017 [cited 2020 Jul 15]; 11(supl. 7):2907-15. Available from: https://periodicos.ufpe.br/revistas/revistaenfermagem/article/view/9518.

26. Caprini FR, Motta AB. Childhood cancer: diagnosis impact analysis. Psicol. rev. [internet], 2017 [cited 2020 Jul 15]; 19(2):177189. DOI: http://dx.doi.org/10.5935/1980-6906.

27. Negreiros RV, Furtado IS, Vasconcelos CRP, Souza LSB, Vilar MMG, Alves RF. A impotância do apoio familiar para efeticidade no tratamento do câncer infantil uma vivência hospitalar. Rev. Saúde Colet. [internet], 2017 [cited 2020 Fev 15]; 6(2):57-641. Available from: https://docplayer.com.br/72630995.

28. Capurso M, Ragni B. Bridge over troubled water: perspective connections between coping and play in children. Front Psychol. [internet], 2016 [cited 2020 Nov 07]; 7:1953. DOI: https://doi.org/10.3389/fpsyg.2016.01953. 